\title{
Cardiovascular effects of cholecalciferol treatment in dialysis patients - a randomized controlled trial
}

Frank H Mose ${ }^{1,2^{*}}$, Henrik Vase ${ }^{4}$, Thomas Larsen ${ }^{1}$, Anne SP Kancir ${ }^{1}$, Renata Kosierkiewic ${ }^{2}$, Bartlomiej Jonczy ${ }^{2}$, Annebirthe B Hansen ${ }^{3}$, Anna E Oczachowska-Kulik², Ingrid M Thomsen², Jesper N Bech ${ }^{1,2}$ and Erling B Pedersen ${ }^{1,2}$

\begin{abstract}
Background: Patients on chronic dialysis are at increased risk of vitamin D deficiency. In observational studies plasma 25-hydroxyvitamin D (p-25(OH) D) levels are inversely correlated with plasma BNP and adverse cardiovascular outcomes. Whether a causal relation exists has yet to be established. The aim of this study was to test the hypothesis that cholecalciferol supplementation improves cardiac function and reduces blood pressure (BP) and pulse wave velocity (PWV) in patients on chronic dialysis.
\end{abstract}

Methods: In a randomized, placebo-controlled, double-blind study, we investigated the effect of $75 \mu \mathrm{g}$ (3000 IU) cholecalciferol daily for 6 months, in patients on chronic dialysis. We performed two-dimensional echocardiography, with doppler and tissue-doppler imaging, 24-h ambulatory BP (24-h BP), PWV, augmentation index (Alx), central BP (CBP) and brain natriuretic peptide (BNP) measurements at baseline and after 6 months.

Results: Sixty-four patients were allocated to the study. Fifty dialysis patients with a mean age of 68 years (range: $46-88)$ and baseline $\mathrm{p}-25(\mathrm{OH}) \mathrm{D}$ of $28(20 ; 53) \mathrm{nmol} / \mathrm{l}$ completed the trial. Cholecalciferol increased left ventricular (LV) volume, but had no impact on other parameters regarding LV structure or left atrial structure. LV systolic function, LV diastolic function, PWV, cBP, Alx and BNP were not changed in placebo or cholecalciferol group at follow-up. 24-h BP decreased significantly in placebo group and tended to decrease in cholecalciferol group without any difference between treatments.

Conclusion: Six months of cholecalciferol treatment in patients on chronic dialysis did not improve 24-h BP, arterial stiffness or cardiac function.

Trial registration: NCT01312714, Registration Date: March 9, 2011.

Keywords: Cholecalciferol, Chronic kidney disease, Cardiac function, Brain natriuretic peptide, Blood pressure

\section{Background}

Patients with CKD have profound reductions in plasma levels of both 25-hydroxyvitamin D [25(OH) D] and the more potent 1,25 dihydroxyvitamin $\mathrm{D}\left[1,25(\mathrm{OH})_{2} \mathrm{D}\right]$ [1-4]. In patients with $\mathrm{CKD}$, low $25(\mathrm{OH}) \mathrm{D}$ levels are associated with higher brain natriuretic peptide (BNP) levels [5], increased cardiovascular events [6,7] and increased mortality [8]. However, these observations are prone to confounding, because healthier people may spend more time outdoors.

\footnotetext{
* Correspondence: frchri@rm.dk

${ }^{1}$ University Clinic in Nephrology and Hypertension, Department of Medical Research and University of Aarhus, Holstebro Hospital, Holstebro, Denmark ${ }^{2}$ Department of Medicine, Holstebro Hospital, Laegaardvej 12, Holstebro 7500, Denmark

Full list of author information is available at the end of the article
}

The importance of vitamin D to mineral metabolism is established but vitamin D may possess beneficial effects on the cardiovascular system in patients with CKD. The vitamin D receptors are widely expressed in human tissues, and recent studies have also found active $1 \alpha-$ hydroxylase in extra-renal tissues, in including cardiac tissue [9] and vascular smooth muscle cells $[10,11]$. In addition, extra-renal produced $1,25(\mathrm{OH})_{2} \mathrm{D}$ seems to have important paracrine and autocrine effects [12,13], which may be highly relevant in patients with reduced renal mass and impaired renal $1,25(\mathrm{OH})_{2} \mathrm{D}$ production.

Active vitamin $\mathrm{D}$ analogue treatment is associated with improved survival in dialysis patients [14], and in spontaneously hypertensive rats active Vitamin D analogues prevented left ventricular hypertrophy [15]. In dialysis 
patients plasma brain natriuretic peptide ( $\mathrm{p}-\mathrm{BNP})$ is a predictor of all-cause mortality [16] and cholecalciferol supplementation was associated with reduced p-BNP and reduced left ventricular mass (LVM) $[3,17]$.

Randomized controlled trials establishing the effect of cholecalciferol supplementation on cardiac function and BP in patients with CKD are still mandated. The aim of this study was to test the hypothesis that cholecalciferol supplementation improves cardiac function and reduces BNP, 24 hour ambulatory BP (24-h BP) and pulse wave velocity (PWV) in patients with stage 5 CKD on chronic dialysis.

\section{Methods}

\section{Study population}

Subjects passed a screening examination that included medical history and physical examination. Inclusion criteria: Both men and women, age above 18 years, dialysis treatment for more than 3 months. Exclusion criteria: Current malignant disease, hypercalcemia (albumin corrected serum calcium $>2.60 \mathrm{mmol} / \mathrm{L}$ ), allergy or intolerance towards cholecalciferol tablets, incapability to give informed consent. Withdrawal criteria: Renal transplantation, non-compliance, clinical complications rendering oral ingestion of tablets or trial completion impossible, transferral to another dialysis department and withdrawal of informed consent.

\section{Design}

The study was a single-center, randomized, placebocontrolled, double blinded, trial. After inclusion subjects were allocated to treatment via computer-generated randomization in blocks of ten and received 3000 IU $(75 \mu \mathrm{g})$ cholecalciferol daily or placebo for 6 months.

\section{Study drugs}

Cholecalciferol and placebo were identical in appearance and were given orally and were obtained from Ferrosan A/S, Soeborg, Denmark.

\section{Ethics}

The study was approved by the Regional Committee on Biomedical Research Ethics, and carried out in accordance with the Declaration of Helsinki. Written, informed consent was obtained from each subject.

\section{Effect variables}

The main effect variable was $\mathrm{p}-\mathrm{BNP}$. Other effect variables were 24-h BP, central diastolic BP (cDBP), central systolic BP (cSBP), PWV, AIx and plasma concentrations of renin (PRC), angiontensin II (p-AngII), aldosterone (p-Aldo), 25 $(\mathrm{OH}) \mathrm{D}$, intact parathyroid hormone (p-PTH), ionized calcium $\left(\mathrm{p}-\mathrm{Ca}^{2+}\right)$, phosphate ( $\mathrm{p}$-phosphate), alkaline phosphatase and $\mathrm{C}$-reactive protein ( $\mathrm{p}-\mathrm{CRP})$. In echocardiography, structural parameters included left ventricular mass index (LVMI), Left ventricular (LV) wall thickness and LV diastolic volume and diameter and functional parameters. Functional parameters included LV Ejection Fraction, LV longitudinal function assessed by tissue Doppler, LV global and local strain assessed by 2D Speckle Tracking, and LV diastolic function assessed by early mitral inflow wave velocity/early diastolic mitral annular velocity ratio (E/e'), early/late mitral inflow wave velocity ratio (E/A) and E-wave deceleration time.

\section{Recruitment}

Patients were consecutively recruited from the Dialysis Department and Outpatients' Clinic of Renal Diseases, Holstebro Hospital All patients in our dialysis department were screened for participation.

\section{Number of subjects}

With a significance level of $5 \%$ and a power of $80 \%$ a total of 56 subjects (28 in each group) were needed to detect a $15 \mathrm{pmol} / \mathrm{l}$ difference in p-BNP (SD $20 \mathrm{pmol} / \mathrm{l}$ ). The aim was to include 80 patients due to an expected withdrawal of $25 \%$. The power calculation was based on previous observational data of cholecalciferol supplementation in hemodialysis patients) [3].

\section{Experimental procedure}

Vitamin D supplementation of more than $10 \mu \mathrm{g}$ of ergo- or cholecalciferol daily was paused 3 months prior to allocation treatment group and baseline measurements. Transthoracic echocardiography (TTE), applanation tonometry and 24-h BP was performed at baseline and repeated after 6 months of treatment. Measurements were performed on the same day. After arrival at the research facility, TTE was performed followed by applanation tonometry and venous blood sampling for evaluation of vasoactive hormones (PRC, p-Ang II, p-Aldo, p-AVP and p-BNP). In peritoneal dialysis (PD) patients 24-h BP equipment was mounted after blood sampling. In hemodialysis (HD) patients a regular dialysis was performed after TTE, applanation tonometry and blood sampling, and 24-h BP equipment was mounted after the dialysis session had finished. In HD patients, baseline and follow-up measurements were performed on a dialysis day, with an interdialytic interval as short as possible prior to the measurements. Measurements in PD patients were performed in relation to a visit at the outpatient clinic. At the day of baseline and followup examinations participants took their usual medication, and were not allowed any alcoholic or caffeinated beverages. At baseline and every 4 weeks blood samples were obtained for assessment of plasma concentrations $\mathrm{Ca}^{2+}$, phosphate, PTH and p-25(OH) D.

\section{BP measurements}

24-h BP was measured using Kivex TM-2430 (Kivex, Hoersholm, Denmark). Equipment was mounted after 
cessation of a dialysis session. Measurements were taken every 15 minute during daytime and every 30 minute over night. Brachial blood pressure used for calibration of Sphygmocor system was measure as duplicate recording with Omron 705IT (Omron Matsusaka CO. Ltd., Matsusaka City, Japan). If measurements of the duplicate recording exceeded $7 \mathrm{mmHg}$, the BP measurement was repeated.

\section{TTE measurements}

TTE was performed using a Vivid 7 (GE Medical Systems Inc., Horten, Norway) cardiac ultrasound system. All images were stored for offline analysis. All measures was performed separately, randomly, and blinded to treatment allocation.

Left ventricular (LV) dimensions were obtained from the parasternal long-axis view, with measurement of end-diastolic interventricular septal thickness, LV posterior wall thickness, and LV end-diastolic diameter just below the tips of the anterior mitral leaflet. LV mass was calculated using the Devereux formula and indexed to body surface area to obtain the LV mass index (LVMI) [18]. LV ejection fraction (LVEF) and LV volumes were calculated from conventional apical two- and fourchamber images, using the biplane Simpson technique.

Left atrial (LA) volume was assessed by the biplane area-length method from apical 4- and 2-chamber views at end systole from the frame preceding mitral valve opening. Left atrial volume index was calculated as LA volume to body surface area $(\mathrm{mL} / \mathrm{m} 2)$. Mitral inflow was assessed in the apical 4-chamber view with the pulsed wave Doppler sample volume placed at the tips of mitral leaflets during diastole. From the inflow, peak $\mathrm{E}$ wave velocity, $\mathrm{E}$ wave deceleration time and peak $\mathrm{A}$ wave were measured. Mitral annular motion was assessed using pulsed wave tissue Doppler with the sample volume placed in the septal and lateral mitral annulus. The mean of the septal and lateral e' velocity was used for calculation of E/e'. Global and regional strain was measured by $2 \mathrm{D}$ speckle tracking. All measurements were estimated as averages of three (sinus rhythm) or five (atrial fibrillation) consecutive heart beats.

\section{Applanation tonometry}

After echocardiography, subjects were transferred to the dialysis department and supine position was assumed in a quiet temperature controlled room (temperature range $21-24^{\circ} \mathrm{C}$ ). After 30 minutes supine position, applanation tonometry was performed. Recordings of pulse wave analysis (PWA) and carotid-femoral PWV were obtained by applanation tonometry (SphygmoCor ${ }^{\ominus} \mathrm{CPV}$ system ${ }^{\odot}$, AtCor Medical, Sydney, Australia) as double-recordings by a trained observer. Only duplicate recording meeting the quality requirements were included in the final analysis [19].

\section{Biochemical analyses}

Routine blood samples obtained at baseline and every month through out the study were immediately assayed at the Department of Clinical Biochemistry. Commercial chemiluminescence immunoassays were used to analyze plasma concentrations of $25(\mathrm{OH}) \mathrm{D} 2+25(\mathrm{OH})$ D3 (Liaison, DiaSorin, Saluggia, Italy) and BNP (Centaur, Bayer Germany).

Blood samples for measurements of vasoactive hormones were centrifuged for 10 minutes at $2200 \mathrm{G}$ and $4^{\circ} \mathrm{C}$. Plasma was separated from blood cells and kept frozen until assayed. PRC was determined using an immunoradiometric assay from CIS Bio International, Gif-Sur-Yvette Cedex, France. Minimal detection level was $1 \mathrm{pg} / \mathrm{ml}$. The coefficients of variation were $0.9-3.6 \%$ (intra-assay) and $3.7-5.0 \%$ (inter-assay) in the range of $4-263 \mathrm{pg} / \mathrm{ml}$. Aldo was determined by RIA using a kit from Demeditec Diagnostics $\mathrm{GmbH}$, Kiel, Germany. Minimal detection level was $25 \mathrm{pmol} / \mathrm{l}$. The coefficients of variation were $9.0 \%$ (inter-assay) and $8.5 \%$ (intra-assay). Ang II were extracted from plasma with $\mathrm{C}_{18}$ Sep-Pak (Water associates, Milford, MA, USA), and subsequently determined by radioimmunoassay [20,21]. The antibody against Ang II was obtained from the Department of Clinical Physiology, Glostrup Hospital, Denmark. Minimal detection level was $2 \mathrm{pmol} / \mathrm{L}$. The coefficients of variation were $12 \%$ (inter-assay) and $8 \%$ (intra-assay).

\section{Statistics}

Data are presented as means \pm standard deviations $( \pm \mathrm{SD})$, if they showed normality, and as medians with $25 \%$ and $75 \%$ percentiles in brackets, if normality was not found. Comparisons between groups were performed with unpaired t-test or Mann-Whitney U-test. Paired comparisons within groups were performed with paired t-test or Wilcoxon signed rank test. Pearson's correlation was used to test for significant correlation between changes in $\mathrm{p}-\mathrm{BNP}$ and changes in $\mathrm{p}-25(\mathrm{OH}) \mathrm{D}$. Statistical significance was defined as $\mathrm{p}<0.05$. Statistical analyses were performed using PASW version 20.0.0 (SPSS Inc.; Chicago, IL, USA).

\section{Results}

\section{Demographics}

A total of 140 dialysis patients were screened for participation and 64 patients were included in the trial (Figure 1), and had baseline measurements performed. During the trial 14 patients were with-drawn due to kidney transplantation (3), cerebrovascular disease which made oral ingestion of tablets impossible (3), non-compliance (1), withdrawal of consent (6) or hypercalcemia (1). Thus follow up measurements were performed in 50 patients. Six patients developed hypercalcemia, which was treated within the guidelines of our department. Five of the 


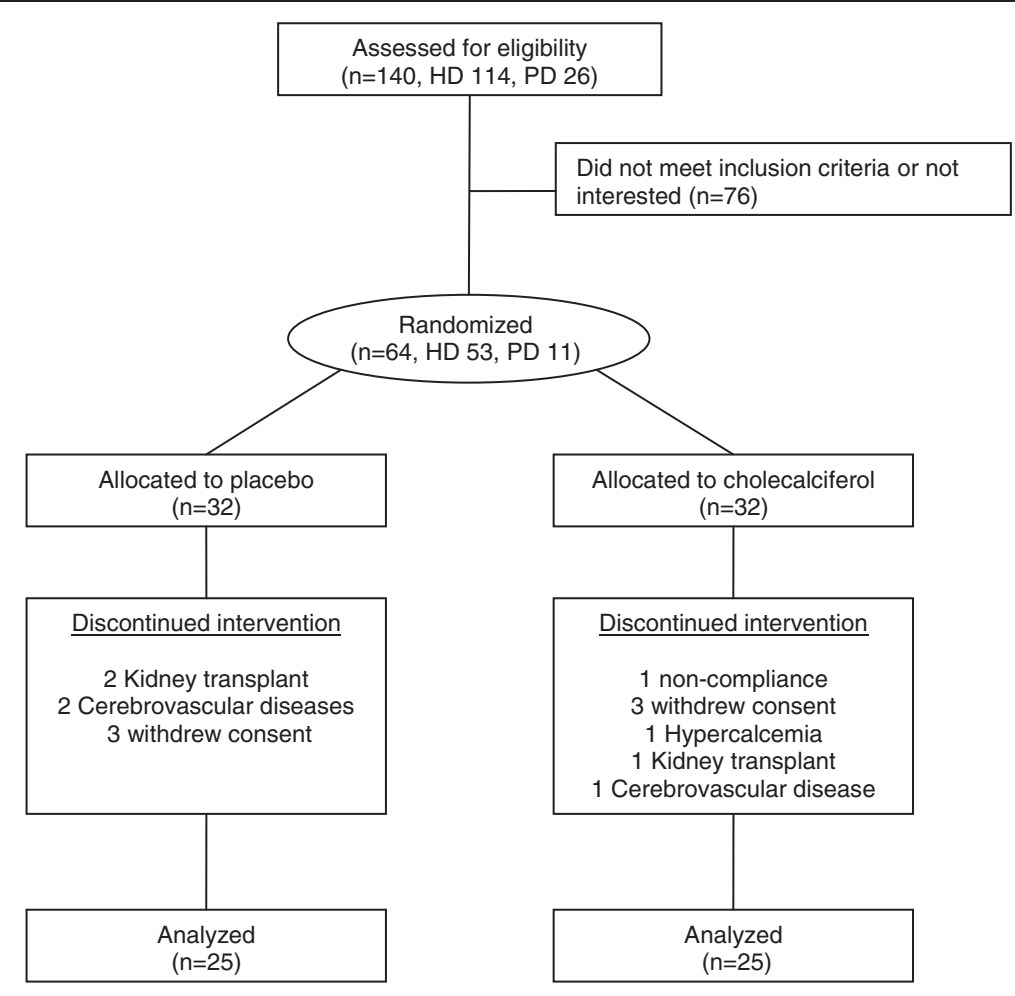

Figure 1 Flow chart.

patients were allocated to the placebo group and one to the cholecalciferol group. The patient in the cholecalciferol group was the patient who was excluded due to persistent hypercalcemia.

Baseline characteristics are shown in Table 1. Baseline p-BNP and p-25(OH) D was similar between groups. At baseline, p-25(OH) D was $<80 \mathrm{nmol} / \mathrm{L}$ in 47 patients $(86 \%)$, and $<50 \mathrm{nmol} / \mathrm{L}$ in 33 patients (66\%). Mean compliance by pill count was $99 \%$ in both groups.

\section{Vasoactive hormones and calcium metabolism}

Changes in p-BNP, PRC, p-Ang II and p-Aldo are given in Table 2. Median changes in p-BNP, p-Ang II, PRC and pAldo between baseline and follow-up did not differ at follow-up or were significantly different between groups. Changes in plasma levels of $25(\mathrm{OH}) \mathrm{D}, \mathrm{PTH}$, phosphate and $\mathrm{Ca}^{2+}$ levels are depicted in Figure 2 with baseline and follow-up values given in Table 2. There was no correlation between changes in p-BNP and changes $\mathrm{p}-25(\mathrm{OH})$ $\mathrm{D}$ from baseline to follow-up $(r=-0.069, \mathrm{p}=0.633)$

\section{4-h BP and arterial stiffness}

No difference in baseline 24-h BP was observed between groups (Table 3). In placebo group 24-h SBP decreased significantly $(-9 \pm 17 \mathrm{mmHg}, \mathrm{p}=0.023)$ and $24-\mathrm{h} \mathrm{DBP}$ insignificantly $(-4 \pm 10 \mathrm{mmHg}, \mathrm{p}=0.068)$. In cholecalciferol group 24-h SBP and 24-h DBP decreased tended to decrease $(-5 \pm 24, \mathrm{p}=0.376$ and $-2 \pm 10 \mathrm{mmHg}$ resp., $\mathrm{p}=$ 0.396). The reductions in 24-h BP were not different between groups. The same pattern was seen for day-time and night-time values with no difference between groups.

CBP and measures of arterial stiffness are documented in Table 4. Data on PWA and PWV were available on 41 and 40 patients, resp. No change between and within groups was found in $\mathrm{CBP}$ and PWV. AIx decreased significantly in placebo group and was unchanged in cholecalciferol group, and the response was significantly different between groups.

\section{Echocardiography}

Transthoracic echocardiography measures at baseline and 6 months follow-up are shown in Table 5.

LV end diastolic volume increased significantly in the cholecalciferol group compared to placebo. Cholecalciferol treatment had no effect on LVEF, LVMI, LAVI, E wave deceleration time, E/A ratio or E/e'. Furthermore cholecalciferol treatment had no impact on mitral plane systolic motion, global or regional strain (data not shown).

\section{Medication}

Changes in calcium supplements, alfacalcidol, paricalcitol, calcimimitecs, phosphate binders and erythropoietin analogues from baseline to follow-up are shown in Table 6. Median changes were 0 for all the drugs in 
Table 1 Baseline characteristics according to randomization in a randomized, placebo-controlled, double-blinded study of $\mathbf{5 0}$ dialysis patients

\begin{tabular}{|c|c|c|c|}
\hline & Placebo & Vitamin-D3 & $P$ value \\
\hline Age (years) & $67 \pm 13$ & $68 \pm 9$ & 0.794 \\
\hline Body mass index $\left(\mathrm{kg} / \mathrm{m}^{2}\right)$ & $23.8 \pm 4.4$ & $24.0 \pm 4.5$ & 0.856 \\
\hline Male sex, $n(\%)$ & $15(60)$ & $17(68)$ & 0.556 \\
\hline \multicolumn{4}{|l|}{ Smokers, $n(\%)$} \\
\hline Current & $5(20)$ & $1(4)$ & 0.220 \\
\hline Former & $5(20)$ & $6(24)$ & \\
\hline Never & $15(60)$ & $18(72)$ & \\
\hline Type 1 diabetes, $n(\%)$ & $4(16)$ & $2(8)$ & 0.384 \\
\hline Type 2 diabetes, $n(\%)$ & $5(20)$ & $2(8)$ & 0.221 \\
\hline $\mathrm{HD}, n(\%)^{\mathrm{A}}$ & $24(96)$ & $19(76)$ & 0.042 \\
\hline $\begin{array}{l}\text { Dialysis sessions pr. week } \\
\text { for HD patients }\end{array}$ & $3.2 \pm 0.6$ & $3.2 \pm 0.6$ & 0.817 \\
\hline \multicolumn{4}{|l|}{ Medication, $n(\%)$} \\
\hline ACEi/ARBS & $17(68)$ & $17(68)$ & 0.914 \\
\hline Calcium channel blockers & $7(28)$ & $13(54)$ & 0.083 \\
\hline Beta blockers & $11(44)$ & $15(60)$ & 0.285 \\
\hline Loop diuretics & $11(44)$ & $12(40)$ & 0.777 \\
\hline Minoxidil & $5(20)$ & $6(24)$ & 0.733 \\
\hline Alfa-blockers & $2(8)$ & $1(4)$ & 0.552 \\
\hline Alfacalcidol & $12(48)$ & $15(60)$ & 0.393 \\
\hline Paricalcitol & $1(4)$ & $1(4)$ & 1.000 \\
\hline Cinecalcet & $2(8)$ & $2(8)$ & 1.000 \\
\hline Phosphate binder & $17(68)$ & $20(80)$ & 0.333 \\
\hline Lanthanum & $3(12)$ & $4(16)$ & 0.684 \\
\hline Sevelamer & $10(40)$ & $14(56)$ & 0.258 \\
\hline Calcium-containing $^{B}$ & $15(60)$ & $17(68)$ & 0.254 \\
\hline Erythropoetin analogue & $24(96)$ & $21(84)$ & 0.157 \\
\hline P-BNP (pmol/L) & $81(24 ; 186)$ & $61(26 ; 378)$ & 0.600 \\
\hline $\mathrm{P}-25(\mathrm{OH}) \mathrm{D}(\mathrm{nmol} / \mathrm{L})$ & $28(20 ; 69)$ & $28(20 ; 48)$ & 0.614 \\
\hline
\end{tabular}

Values are mean \pm SD, $n$ with percentage in brackets or medians with 25 and 75 percentiles in brackets. ACEi: Angiotensin converting enzyme inhibitors, ARB: Angiotensin receptor blocker. BNP: Brain natriuretic peptide, 25(OH): 25-hydroxy-vitamin $D{ }^{A}$ One subject changed from peritoneal dialysis to haemodialysis (HD) after two months and was placed in HD. ${ }^{\mathrm{B}}$ Unikalk or Osvaren.

Table 6, indicating that the dose prescribed at inclusion was continued throughout the study period in a majority of the patients. There was no difference in mean dose change for any of the drugs between groups.

The Number of patients, who had changes in antihypertensive medication, is shown in Table 7. Median changes were 0 for every antihypertensive drug. In placebo group, 33 dose-increases and 16 had dose-reductions were observed, and in cholecalciferol group and in cholecalciferol group 29 dose-increases and 23 dose-reductions were observed.
Table 2 Effect of cholecalciferol (Vitamin D3) treatment on calcium metabolism and vasoactive hormones in a randomized, placebo-controlled study of 50 patients on dialysis

\begin{tabular}{|c|c|c|c|}
\hline & Baseline & 6 months & $\begin{array}{c}\text { P value } \\
\text { (difference } \\
\text { in response) }\end{array}$ \\
\hline \multicolumn{4}{|c|}{$\mathrm{P}-25(\mathrm{OH}) \mathrm{D}(\mathrm{nmol} / \mathrm{L})$} \\
\hline Placebo & $28(20 ; 69)$ & $30(22 ; 50)$ & \multirow{2}{*}{$<0.001$} \\
\hline Cholecalciferol & $28(20 ; 48)$ & $84(65 ; 125)^{*}$ & \\
\hline \multicolumn{4}{|l|}{ P-PTH (pmol/L) } \\
\hline Placebo & $18.0(5.9 ; 30.5)$ & $12.9(8.7 ; 33.7)$ & \multirow{2}{*}{0.986} \\
\hline Cholecalciferol & $13.5(5.8 ; 29.6)$ & $17.4(9.1 ; 35.3)$ & \\
\hline \multicolumn{4}{|l|}{$\mathrm{P}-\mathrm{Ca}^{2+}(\mathrm{mg} / \mathrm{dL})$} \\
\hline Placebo & $1.20 \pm 0.08$ & $1.20 \pm 0.07$ & \multirow{2}{*}{0.724} \\
\hline Cholecalciferol & $1.21 \pm 0.11$ & $1.20 \pm 0.09$ & \\
\hline \multicolumn{4}{|c|}{ P-Phosphate (nmol/L) } \\
\hline Placebo & $1.66 \pm 0.37$ & $1.59 \pm 0.38$ & \multirow{2}{*}{0.103} \\
\hline Cholecalciferol & $1.59 \pm 0.40$ & $1.73 \pm 0.47$ & \\
\hline \multicolumn{4}{|c|}{ P-Alkaline Phosphatase (U/L) } \\
\hline Placebo & $67(51 ; 99)$ & $72(59 ; 93)$ & \multirow{2}{*}{0.393} \\
\hline Cholecalciferol & $70(48 ; 92)$ & $73(48 ; 106)$ & \\
\hline \multicolumn{4}{|l|}{ P-CRP (mg/L) } \\
\hline Placebo & $4.5(1.7 ; 11.7)$ & $2.5(1.6 ; 13.9)$ & \multirow{2}{*}{0.237} \\
\hline Cholecalciferol & $3.4(1.1 ; 13.3)$ & $3.9(1.1 ; 11.3)$ & \\
\hline \multicolumn{4}{|c|}{ P-leukocytes $\left(10^{9} / \mathrm{L}\right)$} \\
\hline Placebo & $6.3(5.2 ; 7.7)$ & $6.3(5.6 ; 7.3)$ & \multirow{2}{*}{0.740} \\
\hline Cholecalciferol & $6.3(5.1 ; 7.5)$ & $5.8(5.2 ; 8.1)$ & \\
\hline \multicolumn{4}{|c|}{ P-Haemoglobin ( $\mathrm{mmol} / \mathrm{L})$} \\
\hline Placebo & $7.3 \pm 0.8$ & $7,3 \pm 0.7$ & \multirow{2}{*}{0.419} \\
\hline Cholecalciferol & $7.4 \pm 0.8$ & $7.2 \pm 0.6$ & \\
\hline \multicolumn{4}{|l|}{ P-BNP (pmol/L) } \\
\hline Placebo & $81(24 ; 186)$ & $50(30 ; 265)$ & \multirow{2}{*}{0.820} \\
\hline Cholecalciferol & $61(26 ; 378)$ & $95(35 ; 363)$ & \\
\hline \multicolumn{4}{|l|}{ PRC (pg/mL) } \\
\hline Placebo & $10(4 ; 19)$ & $8(6 ; 23)$ & \multirow{2}{*}{0.883} \\
\hline Cholecalciferol & $6(4 ; 12)$ & $8(4 ; 20)$ & \\
\hline \multicolumn{4}{|l|}{ P-Ang II (pg/mL) } \\
\hline Placebo & $12(7 ; 23)$ & $15(4 ; 33)$ & \multirow{2}{*}{0.167} \\
\hline Cholecalciferol & $7(3 ; 26)$ & $12(5 ; 60)$ & \\
\hline \multicolumn{4}{|c|}{ P-Aldosterone (pmol/L) } \\
\hline Placebo & $135(49 ; 300)$ & $209(68 ; 329)$ & \multirow{2}{*}{0.415} \\
\hline Cholecalciferol & $125(61 ; 250)$ & $155(76 ; 312)$ & \\
\hline
\end{tabular}

Values are mean \pm SD or medians with 25 and 75 percentiles in brackets. 25(OH): 25-hydroxy-vitamin D, PTH: parathyroid hormone, CRP, C-reactive protein, BNP: Brain natriuretic peptide, PRC: Plasma renin concentration, Ang II: Angiotensin II, $\mathrm{P}$ values represent the probability of a difference in response to treatment between groups. Statistical significant difference from baseline: ${ }^{*}=p<0.001$. 
A

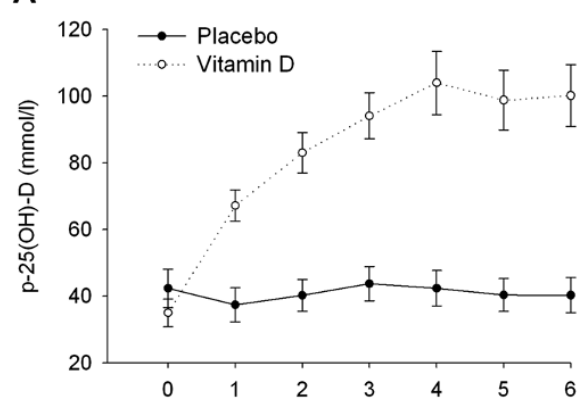

C

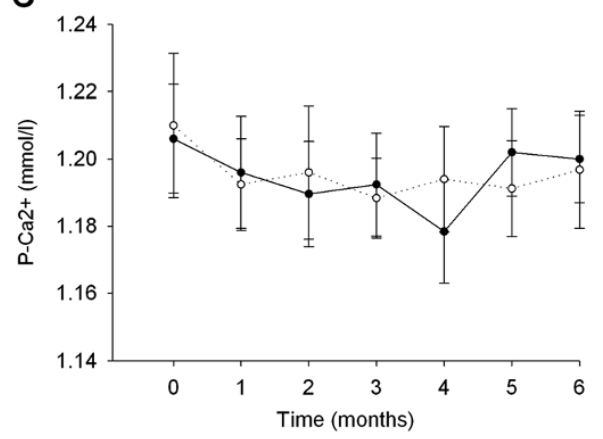

B

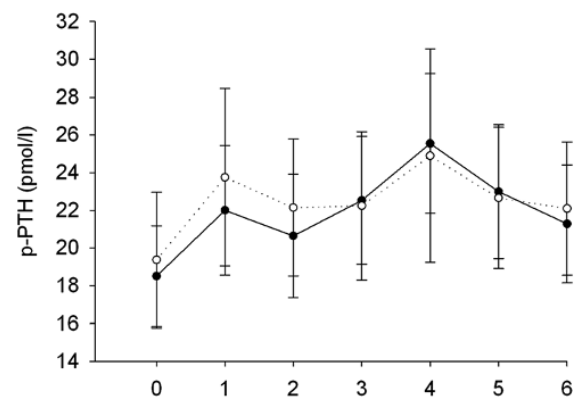

D

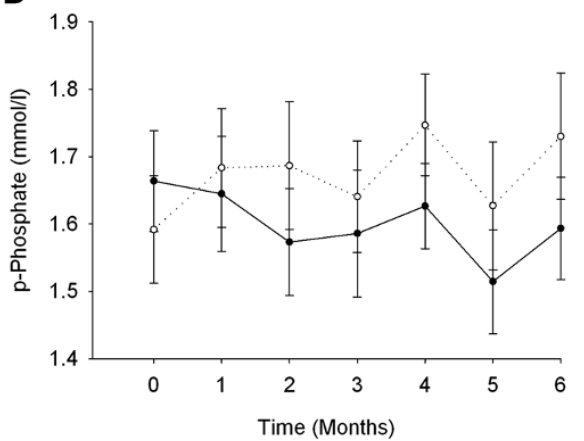

Figure 2 Mean plasma concentrations of 25-hydroxy-vitamin D (p-25(OH)-D) (A), p-PTH (B), plasma ionised calcium (p-Ca $\left.{ }^{2+}\right)(C)$ and p-phosphate (D) with SEM $(n=50)$.

\section{Discussion}

This is the first randomized, placebo-controlled, doubleblinded, single-centre intervention study investigating the effects of cholecalciferol supplementation on cardiac function in dialysis patients. Previous intervention studies, which found indication that cholecalciferol treatment may reduce LVMI and BNP in patients on chronic dialysis, were prospective uncontrolled studies $[3,17]$. We hypothesized that daily cholecalciferol supplementation in dialysis patients improves cardiac function and reduces 24-h BP and arterial stiffness. Cholecalciferol caused a marked increase in $\mathrm{p}-25(\mathrm{OH}) \mathrm{D}$ without increased incidence of hypercalcemia or other adverse effects. After six months, no significant differences were observed in p-BNP, cardiac function, 24-h BP or arterial stiffness between groups.

Previously, intra-venous $1,25(\mathrm{OH})_{2} \mathrm{D}$ (calcitriol) reduced LV hypertrophy in patients on hemodialysis with elevated p-PTH $[22,23]$. Two prospective studies have demonstrated a reduction in LVMI and p-BNP after 6 months of cholecalciferol supplementation $[3,17]$, which is in contrast to our findings where no change was found. In this study 3,000 IU were given daily. Buchales and colleagues administered a higher ( $x$ 1.5) dose and Mathias and colleagues used a substantial higher dose ( $\mathrm{x}$ 2.4) in HD patients with $\mathrm{p}-25(\mathrm{OH}) \mathrm{D}<37 \mathrm{nmol} / \mathrm{L}$ but a lower dose $(\mathrm{x} 0.4-0.5)$ in patients with $\mathrm{p}-25(\mathrm{OH}) \mathrm{D}>37 \mathrm{nmol} / \mathrm{L}$, than we used in this study [3,17]. As in the previous studies, we found an increased in $\mathrm{p}-25(\mathrm{OH}) \mathrm{D}$ levels in response to cholecalciferol supplementation. Dialysis patients have reduced renal mass and reduced renal $1 \alpha$-hydroxylase activity [24], and although cholecalciferol supplementation increased p-1,25 $(\mathrm{OH})_{2} \mathrm{D}$ in patients on dialysis, the increase is impaired compared to non-dialysis populations $[1,3,25,26]$. Vitamin $\mathrm{D}$ receptors and $1 \alpha$-hydroxylase is present in cardiac tissue [9,27], but the increase in $\mathrm{p}-1,25(\mathrm{OH}) \mathrm{D}$ may not be sufficient to activate the vitamin $\mathrm{D}$ receptor in cardiac tissue, with the doses used in this study. However, antihypertensive medication was changed during the study, which could conceal the effects of cholecalciferol.

We found an increase in LV end-diastolic volume after 6 months of cholecalciferol treatment compared to placebo. This is not a beneficial effect, but the difference is small and there were no differences with-in groups from baseline to follow-up in LV end-diastolic volume. This could be by chance and further studies will have to clarify this.

Studies evaluating the effect of cholecalciferol on BP have shown mixed results [28-30]. Two recent trials in hypertensive patients measured BP as 24-h BP, and could not demonstrate reductions in BP by cholecalciferol supplementation [31,32], but a sub-group analysis of $25(\mathrm{OH}) \mathrm{D}$ deficient patients showed a small but significant reduction in 24-h BP [31]. We found a tendency 
Table 3 Effect of 6 months cholecalciferol treatment 24 hour blood pressure (24-h BP) in a randomized, placebo-controlled study of $\mathbf{5 0}$ patients on dialysis

\begin{tabular}{|c|c|c|c|}
\hline & Baseline & 6 months & $\begin{array}{c}\text { P value } \\
\text { (difference } \\
\text { in response }\end{array}$ \\
\hline \multicolumn{4}{|l|}{ 24-h SBP (mmHg) } \\
\hline Placebo & $136 \pm 22$ & $127 \pm 23^{\dagger}$ & \multirow{2}{*}{0.511} \\
\hline Cholecalciferol & $135 \pm 18$ & $130 \pm 14$ & \\
\hline \multicolumn{4}{|l|}{ 24-h DBP (mmHg) } \\
\hline Placebo & $73 \pm 10$ & $69 \pm 10$ & \multirow{2}{*}{0.451} \\
\hline Cholecalciferol & $73 \pm 9$ & $71 \pm 8$ & \\
\hline \multicolumn{4}{|c|}{ 24-h heart rate (bpm) } \\
\hline Placeb & $74 \pm 8$ & $74 \pm 7$ & \multirow{2}{*}{0.464} \\
\hline Cholecalciferol & $70 \pm 9$ & $71 \pm 8$ & \\
\hline \multicolumn{4}{|c|}{ 24-h daytime SBP $(\mathrm{mmHg})$} \\
\hline Placebo & $138 \pm 22$ & $130 \pm 22^{\dagger}$ & \multirow{2}{*}{0.504} \\
\hline Cholecalciferol & $137 \pm 18$ & $133 \pm 15$ & \\
\hline \multicolumn{4}{|c|}{ 24-h daytime DBP (mmHg) } \\
\hline Placebo & $75 \pm 11$ & $71 \pm 11$ & \multirow{2}{*}{0.519} \\
\hline Cholecalciferol & $74 \pm 9$ & $72 \pm 8$ & \\
\hline \multicolumn{4}{|c|}{ 24-h daytime heart rate (bpm) } \\
\hline Placebo & $75 \pm 8$ & $76 \pm 8$ & \multirow{2}{*}{0.586} \\
\hline Cholecalciferol & $71 \pm 9$ & $73 \pm 9$ & \\
\hline \multicolumn{4}{|c|}{ 24-h nighttime SBP $(\mathrm{mmHg})$} \\
\hline Placebo & $131 \pm 26$ & $121 \pm 27^{\dagger}$ & \multirow{2}{*}{0.498} \\
\hline Cholecalciferol & $129 \pm 19$ & $125 \pm 17$ & \\
\hline \multicolumn{4}{|c|}{ 24-h nighttime DBP (mmHg) } \\
\hline Placebo & $69 \pm 11$ & $65 \pm 11^{\dagger}$ & \multirow{2}{*}{0.361} \\
\hline Cholecalciferol & $69 \pm 9$ & $68 \pm 11$ & \\
\hline \multicolumn{4}{|c|}{ 24-h nighttime heart rate (bpm) } \\
\hline Placebo & $70 \pm 8$ & $70 \pm \pm 6$ & \multirow{2}{*}{0.270} \\
\hline Cholecalciferol & $67 \pm 9$ & $69 \pm \pm 9$ & \\
\hline
\end{tabular}

Values are means $\pm S D$. $P$ values represent the probability of a difference in response to treatment between groups. Statistics are performed with t-test. Statistical significant difference from baseline compared with paired t-test. Statistical significant difference from baseline: ${ }^{\dagger}=p<0.05$.

towards a reduction of 24-h BP in cholecalciferol group, but surprisingly an even larger and significant reduction in $\mathrm{BP}$ in the placebo group. Blood pressure medication was recorded at baseline and follow-up. In the placebo group, 33 dose-increases and 16 dose-reductions (difference of 17) were recorded and in cholecalciferol group 29 dose-increases and 23 dose-reductions (difference of 6) were observed. There seems to be a majority of doseincreases in the placebo group, which might explain the reduction in $\mathrm{BP}$ seen in placebo group. In hemodialysis patients $\mathrm{BP}$ is shown to increase in the inter-dialysis period [33]. Since BP is dependent on volume status, an improvement of volemic state might explain the reduction
Table 4 Effect of 6 months cholecalciferol treatment on pulse wave velocity (PWV), augmentation index (Alx), and central diastolic and systolic blood pressure (CDBP, CSBP) in a randomized, placebo-controlled study of $\mathbf{5 0}$ patients on dialysis

\begin{tabular}{lccc}
\hline & Baseline & $\mathbf{6}$ months & $\begin{array}{c}\text { P value } \\
\text { (difference } \\
\text { in response) }\end{array}$ \\
\hline PWV (m/s) & & & \\
$\quad$ Placebo $(n=19)$ & $10.0 \pm 2.0$ & $10.1 \pm 2.5$ & 0.269 \\
$\quad$ Cholecalciferol $(n=22)$ & $9.7 \pm 2.5$ & $10.5 \pm 4.0$ & \\
Alx (\%) & & & \\
$\quad$ Placebo $(n=22)$ & $26.4 \pm 11.5$ & $22.2 \pm 11.2^{\dagger}$ & 0.013 \\
$\quad$ Cholecalciferol $(n=18)$ & $22.1 \pm 9.7$ & $24.6 \pm 12.7$ & \\
CSBP (mmHg) & & & \\
$\quad$ Placebo $(n=22)$ & $127 \pm 24$ & $126 \pm 26$ & 0.744 \\
$\quad$ Cholecalciferol $(n=18)$ & $128 \pm 14$ & $125 \pm 17$ & \\
CDBP (mmHg) & & & \\
$\quad$ Placebo $(n=22)$ & $68 \pm 11$ & $70 \pm 11$ & 0.779 \\
Cholecalciferol $(n=18)$ & $71 \pm 9$ & $71 \pm 12$ & \\
\hline
\end{tabular}

Values are means \pm SD or medians with 25 and 75 percentiles in brackets. Statistics are performed with t-test. P values represent the probability of a difference in response to treatment between groups: Significant difference from baseline: ${ }^{\dagger}=p<0.05$

in BP. Hence, changes in 24-h BP are likely related to changes in medication and volume status. Our results do not suggest a benefit of cholecalciferol supplementation on 24-BP, but BP reductions may induced by cholecalciferol may be concealed by changes in volume status and medication. Thus, we can not exclude that cholecalciferol might have beneficial effects on BP.

PWV is a predictor for all-cause and cardiovascular mortality in patients with end-stage renal disease [34] and we found no change in PWV in the groups at follow-up, which is in agreement with previous reports $[1,35]$. PWV tends to increase in the inter-dialysis period [36], most likely due to volume expansion. Hemodialysis patients had PWV measurements performed just prior to a dialysis session where volume-expansion is at its highest and this could conceal effects of cholecalciferol treatment. AIx decreased significantly in placebo group and was unchanged in cholecalciferol group. Most likely this is explained by the lower 24-h BP in the placebo group. Previously cholecalciferol supplementation did not change AIx [1], and this needs further clarification.

Vitamin D may play an important role in the modulation of renin-angiotensin system in patients on dialysis. In vitamin D receptor knock-out mice renin expression is highly increased leading to hypertension and LV hypertrophy [37] and in mice active vitamin D analogue treatment suppresses renin expression, independent of PTH [38]. In dialysis patients, high dose intravenous vitamin D analogue treatment led to a significant reduction in PRC 
Table 5 Effect of six months cholecalciferol treatment on cardiac structure and function measured by transthoracic echocardiography in a randomized, placebo-controlled study of patients on dialysis

Left ventricular end-diastolic volume (biplane), $\mathbf{m l}$
Placebo $(n=24)$
Cholecalciferol $(n=22)$

Left ventricular ejection fraction (biplane), \%

$$
\text { Cholecalciferol }
$$

Left ventricular mass index, $\mathrm{g} / \mathrm{m} 2$

$$
\begin{aligned}
& \text { Placebo } \\
& \text { Cholecalciferol }
\end{aligned}
$$$$
\text { Baseline } 6 \text { months } P \text { value (difference in response) }
$$

Left atrial volume index, $\mathrm{ml} / \mathrm{m} 2$

$$
\text { Placebo }
$$

Cholecalcifero

Early/late mitral inflow wave velocity ratio (E/A)

Placebo

Cholecalciferol

Transmitral E-wave deceleration time, s

$$
\begin{aligned}
& \text { Placebo } \\
& \text { Cholecalciferol }
\end{aligned}
$$

Early mitral inflow wave velocity/early diastolic mitral annular velocity ratio $\left(E / e^{\prime}\right)$

$$
\begin{array}{lll}
\text { Placebo } & 12 \pm 6 & 13 \pm 5 \\
\text { Cholecalciferol } & 15 \pm 8 & 17 \pm 9
\end{array}
$$

$$
\begin{array}{ll}
52 \pm 14 & 52 \pm 17 \\
53 \pm 14 & 56 \pm 12
\end{array}
$$$$
\begin{array}{ll}
116 \pm 36 & 111 \pm 39 \\
123 \pm 34 & 127 \pm 50
\end{array}
$$

$$
35 \pm 14 \quad 37 \pm 14
$$$$
40 \pm 16 \quad 41 \pm 14
$$

\begin{tabular}{|c|c|c|c|c|c|c|c|c|c|}
\hline & \multicolumn{2}{|c|}{ Vitamin $D$ analogues } & \multirow{2}{*}{$\begin{array}{l}\text { Calcimimetic } \\
\text { Cinecalcet }\end{array}$} & \multicolumn{4}{|c|}{ Phospahte binders } & \multicolumn{2}{|c|}{$\begin{array}{l}\text { Erythropoietin } \\
\text { analogues }\end{array}$} \\
\hline & Alfacalcidol & Paricalcitol & & Unikalk $^{A}$ & Sevelamer & Lanthanum & Osvaren $^{\mathrm{B}}$ & Epoetin & Darbapeotin \\
\hline \multicolumn{10}{|l|}{$\begin{array}{l}\text { Placebo (changes } \\
\text { from baseline) }\end{array}$} \\
\hline Increased dose $(n)$ & 7 & 0 & 1 & 0 & 6 & 1 & 7 & 1 & 7 \\
\hline Same dose $(n)$ & 10 & 25 & 23 & 22 & 13 & 23 & 12 & 23 & 6 \\
\hline Reduced dose (n) & 8 & 0 & 1 & 3 & 6 & 1 & 6 & 1 & 12 \\
\hline Mean change in dose & $\begin{array}{l}0.2 \pm 4.3 \\
\mu \mathrm{g} / \text { week }\end{array}$ & $\begin{array}{c}0 \pm 0 \\
\mu \mathrm{g} / \text { week }\end{array}$ & $\begin{array}{l}0.0 \pm 26 \\
\mathrm{mg} / \text { day }\end{array}$ & $\begin{array}{l}-0.4 \pm 1.0 \\
\text { tablets/day }\end{array}$ & $\begin{array}{l}0.0 \pm 2.4 \\
\text { g/day }\end{array}$ & $\begin{array}{l}30 \pm 340 \\
\mathrm{mg} / \text { day }\end{array}$ & $\begin{array}{l}-0.1 \pm 2.8 \\
\text { tablets/day }\end{array}$ & $\begin{array}{l}160 \pm 2939 \\
\text { IU/week }\end{array}$ & $\begin{array}{l}-4.8 \pm 22.6 \\
\mu \mathrm{g} / \text { week }\end{array}$ \\
\hline \multicolumn{10}{|l|}{$\begin{array}{l}\text { Cholecalciferol } \\
\text { (changes from baseline) }\end{array}$} \\
\hline Increased dose (n) & 8 & 1 & 1 & 2 & 3 & 3 & 3 & 0 & 9 \\
\hline Same dose $(n)$ & 12 & 23 & 22 & 17 & 14 & 18 & 17 & 25 & 6 \\
\hline Reduced dose (n) & 5 & 1 & 2 & 6 & 8 & 4 & 5 & 0 & 10 \\
\hline Mean change in dose & $\begin{array}{l}0.7 \pm 3.0 \\
\mu \mathrm{g} / \text { week }\end{array}$ & $\begin{array}{c}0 \pm 4 \\
\mu \mathrm{g} / \text { week }\end{array}$ & $\begin{array}{c}-2.4 \pm 21 \\
\mathrm{mg} / \mathrm{day}\end{array}$ & $\begin{array}{l}-0.6 \pm 1.4 \\
\text { tablets/day }\end{array}$ & $\begin{array}{l}-0.6 \pm 1.8 \\
\text { g/day }\end{array}$ & $\begin{array}{l}30 \pm 931 \\
\mathrm{mg} / \text { day }\end{array}$ & $\begin{array}{l}-0.4 \pm 2.0 \\
\text { tablets/day }\end{array}$ & $\begin{array}{c}0 \pm 0 \\
\text { IU/week }\end{array}$ & $\begin{array}{l}3.2 \pm 34.0 \\
\mu \mathrm{g} / \text { week }\end{array}$ \\
\hline
\end{tabular}

$0.84 \pm 0.21 \quad 0.89 \pm 0.28$

$1.10 \pm 0.59 \quad 1.21 \pm 0.72$

$$
\begin{array}{ll}
228 \pm 92 & 230 \pm 76 \\
226 \pm 62 & 215 \pm 61
\end{array}
$$

Values are means $+S D$. P values represent the probability of a difference in response to treatment between groups. Data was available for 24 patients in cholecalciferol group and 22 patients in the placebo group. Statistics are performed with t-test. Statistical significant difference from baseline compared with paired t-test.

Table 6 Changes in calcium supplements, alfacalcidol, paricalcitol, calcimimitecs, phosphate binders and erythropoietin analogues in a randomized, placebo-controlled study investigating the effects of cholecalciferol supplementation for 6 months in 50 patients on dialysis

Mean change in dose is shown as mean \pm SD A One tablet contains 1000 mg calcium acetate ${ }^{\mathrm{B}}$ One tablet contains $435 \mathrm{mg}$ calcium acetate and $235 \mathrm{mg}$ magnesium carbonate. 
Table 7 Changes in antihypertensive mediation in a randomized, placebo-controlled study investigating the effects of cholecalciferol supplementation for 6 months in 50 patients on dialysis

\begin{tabular}{|c|c|c|c|c|c|c|c|c|}
\hline Changes from baseline & $\begin{array}{c}\text { ACE- } \\
\text { inhibitor }\end{array}$ & $\begin{array}{c}\text { AT2- } \\
\text { antagonist }\end{array}$ & $\begin{array}{c}\text { Calcium- } \\
\text { antagonist }\end{array}$ & $\begin{array}{c}\text { Beta- } \\
\text { blocker }^{A}\end{array}$ & Fourosemide & Minoxidil & $\begin{array}{c}\text { Alfa- } \\
\text { blocker }\end{array}$ & Moxonidine \\
\hline \multicolumn{9}{|l|}{ Placebo } \\
\hline Increased dose $(n)$ & 6 & 4 & 4 & 9 & 6 & 4 & 0 & 0 \\
\hline Same dose $(n)$ & 18 & 19 & 19 & 14 & 15 & 16 & 25 & 25 \\
\hline Reduced dose (n) & 1 & 2 & 2 & 2 & 4 & 5 & 0 & 0 \\
\hline \multicolumn{9}{|l|}{ Cholecalciferol } \\
\hline Increased dose $(n)$ & 3 & 5 & 3 & 4 & 7 & 4 & 2 & 1 \\
\hline Same dose $(n)$ & 16 & 19 & 18 & 18 & 14 & 18 & 23 & 22 \\
\hline Reduced dose $(n)$ & 6 & 1 & 4 & 3 & 4 & 3 & 0 & 2 \\
\hline
\end{tabular}

ACE: Angiotensin converting enzyme, AT2: Angiotensin 2. ${ }^{\mathrm{A}} 1$ patient in placebo and 1 patient in cholecalciferol group had metroprolol substituted with carvedilol in equivalent doses and is reported as given same dose beta-blocker.

and p-Ang II [23]. In contrast, PRC and p-Ang II was unchanged after active vitamin D analogue supplementation in patients with CKD stage III-IV [39] and type 2 diabetics with nephropathy [40] and after 6 months oral cholecalciferol supplementation in hypertensives [31]. This is in agreement with the finding in the present trial. Although we recorded no effect of cholecalciferol on circulating concentrations, these measurements might not be accurate indicators of renin or angiotensin II activity within the kidney in response to cholecalciferol. In addition, given that patients were non-fasting and $68 \%$ were on angiotensin II receptor blocker or angiotensin-converting enzyme inhibitor, conclusions regarding changes in the RAS should be made with caution.

Previous conclusions from clinical trials regarding the effect of vitamin D supplementation on PTH in dialysis patients are inconsistent, with both suppressed [3,41,42] and unchanged PTH [1,35,43-45] observed. In this study, cholecalciferol plasma concentrations of calcium, phosphate and PTH were unchanged. However, in this trial setting the effect of cholecalciferol treatment is very difficult to estimate. Cholecalciferol was used on top of usual treatment and changes in p-calcium, p-phosphate and PTH during the trial were regulated tightly with-in the usual guidelines of our department. Although medication changes regarding calcium and phosphate metabolism in the 6 month treatment period were small and did not seem different between groups, potential changes in plasma concentrations of phosphate, calcium and PTH are most likely concealed by medication changes.

Oral supplementation of 3,000 IU cholecalciferol daily was highly effective in restoring p-25(OH) D levels without increasing the risk of hypercalcemia or other adverse effects. The incidence of persistent hypercalcemia, was after the trial was finished associated with malignant disease, and was most likely not related to cholecalciferol supplementation.
The design as a randomised, placebo-controlled, doubleblinded, single-centre trial was an essential strength of the present study. Compliance to study medication, documented by pill count, was high and a relatively high cholecalciferol was given.

Usual dialysis and medical treatment, except nutritional vitamin D supplementation, was continued during study period, and adjusted as clinically warranted during the course of the trial. We did not find it ethically justified to discontinue usual medication or with-hold optimal treatment. Thus, the study was performed under optimal care, and this may influence effect variables and conceal the effects of cholecalciferol treatment. Patients were included regardless of their p-25(OH) D levels. Thus, some patients were had sufficient vitamin D levels. In patients with sufficient vitamin D levels, raising vitamin D levels further may not change outcomes, and this could conceal potential beneficial effects of cholecalciferol supplementation in vitamin deficient patients. Further investigations in vitamin $\mathrm{D}$ deficient dialysis patients are needed the address this problem.

We have not performed sub-group analysis since this study was not powered for such analysis. For instance, both patients on HD and PD were included in this study, but the study was not powered to reveal a difference in response to cholecalciferol between the different dialysis modalities. Hence, it cannot be excluded that certain sub-groups might benefit from cholecalciferol supplementation.

This study was powered to detect a difference in pBNP. For some of the secondary effect variables this study may not have sufficient power to detect a difference. We cannot exclude that a bigger sample size could reveal differences in some of the secondary effect variables.

\section{Conclusions}

In conclusion, six months of cholecalciferol treatment in patients on chronic dialysis did not improve 24-h BP, 
arterial stiffness or cardiac function. The study population was a heterogeneous group of patients on dialysis on usual medication, and although we did not find beneficial effects of cholecalciferol supplementation, certain subgroups could benefit from cholecalciferol supplementation. Further studies are warranted to evaluate this.

\section{Competing interests}

All authors declare no conflict of interests. Ferrosan A/S supplied cholecalciferol and placebo free of charge, but did not play any role in the study.

\section{Authors' contributions}

FHM, TL, JNB and EBP designed the project. BJ, RK and HV performed echocardiography, TL, FHM. IMT, AEO, JNB, and EBP recruited and had daily contact to patients. $\mathrm{ABH}$ were responsible for measurements of $\mathrm{p}-25(\mathrm{OH})$, p-PTH, p-BNP and routine laboratory analyses. EBP was responsible for measurements of PRC, $\mathrm{p}$-Ang $\|$ and $\mathrm{p}$-Aldo. FHM and TL were responsible for applanation tonometry measurements. FHM, TL, ASPK, IMT, AEO, JNB and EBP were responsible for $24-\mathrm{h}$ BP measurements. FHM wrote the primary draft. The final manuscript was prepared in collaboration between FHM, HV $\mathrm{TL}, \mathrm{JNB}$ and EBP. All authors read and approved the final manuscript.

\section{Acknowledgements}

We are deeply thankful for the time and conscientious efforts put into this study by our participants. We also want to acknowledge the skilful technical assistance of our laboratory team, including, Anne Mette Ravn, Henriette Vorup Simonsen and Kirsten Nyborg.

\section{Author details}

${ }^{1}$ University Clinic in Nephrology and Hypertension, Department of Medical Research and University of Aarhus, Holstebro Hospital, Holstebro, Denmark. ${ }^{2}$ Department of Medicine, Holstebro Hospital, Laegaardvej 12, Holstebro 7500, Denmark. ${ }^{3}$ Department of Clinical Biochemistry, Holstebro Hospital, Holstebro, Denmark. ${ }^{4}$ Department of Cardiology, Aarhus University Hospital, Aarhus, Denmark.

\section{Received: 12 October 2013 Accepted: 20 March 2014}

Published: 24 March 2014

\section{References}

1. Marckmann P, Agerskov H, Thineshkumar S, Bladbjerg EM, Sidelmann JJ, Jespersen J, Nybo M, Rasmussen LM, Hansen D, Scholze A: Randomized controlled trial of cholecalciferol supplementation in chronic kidney disease patients with hypovitaminosis D. Nephrol Dial Transplant 2012, 27:3523-3531

2. Patel NM, Gutierrez OM, Andress DL, Coyne DW, Levin A, Wolf M: Vitamin D deficiency and anemia in early chronic kidney disease. Kidney Int 2010 77:715-720

3. Matias PJ, Jorge C, Ferreira C, Borges M, Aires I, Amaral T, Gil C, Cortez J, Ferreira A: Cholecalciferol supplementation in hemodialysis patients: effects on mineral metabolism, inflammation, and cardiac dimension parameters. Clin J Am Soc Nephrol 2010, 5:905-911.

4. Singer RF: Vitamin D in dialysis: defining deficiency and rationale for supplementation. Semin Dial 2013, 26:40-46.

5. Matias PJ, Ferreira C, Jorge C, Borges M, Aires I, Amaral T, Gil C, Cortez J, Ferreira A: 25-Hydroxyvitamin D3, arterial calcifications and cardiovascular risk markers in haemodialysis patients. Nephrol Dia Transplant 2009, 24:611-618.

6. Drechsler C, Verduijn M, Pilz S, Dekker FW, Krediet RT, Ritz E, Wanner C, Boeschoten EW, Brandenburg V: Vitamin D status and clinical outcomes in incident dialysis patients: results from the NECOSAD study. Nephrol Dial Transplant 2011, 26:1024-1032.

7. Wang AY, Lam CW, Sanderson JE, Wang M, Chan IH, Lui SF, Sea MM, Woo J: Serum 25-hydroxyvitamin D status and cardiovascular outcomes in chronic peritoneal dialysis patients: a 3-y prospective cohort study. Am J Clin Nutr 2008, 87:1631-1638.

8. Pilz S, lodice S, Zittermann A, Grant WB, Gandini S: Vitamin D status and mortality risk in CKD: a meta-analysis of prospective studies. Am J Kidney Dis 2011, 58:374-382.
9. Zhou C, Lu F, Cao K, Xu D, Goltzman D, Miao D: Calcium-independent and $1,25(\mathrm{OH}) 2 \mathrm{D} 3$-dependent regulation of the renin-angiotensin system in 1alpha-hydroxylase knockout mice. Kidney Int 2008, 74:170-179.

10. Adams JS, Hewison M: Extrarenal expression of the 25-hydroxyvitamin D-1-hydroxylase. Arch Biochem Biophys 2012, 523:95-102.

11. Somjen D, Weisman Y, Kohen F, Gayer B, Limor R, Sharon O, Jaccard N, Knoll E, Stern N: 25-hydroxyvitamin D3-1alpha-hydroxylase is expressed in human vascular smooth muscle cells and is upregulated by parathyroid hormone and estrogenic compounds. Circulation 2005, 111:1666-1671.

12. Jones $\mathrm{G}$ : Extrarenal vitamin d activation and interactions between vitamin d2, vitamin d3, and vitamin d analogs. Annu Rev Nutr 2013, 33:23-44.

13. Liu PT, Stenger S, Li H, Wenzel L, Tan BH, Krutzik SR, Ochoa MT, Schauber J Wu K, Meinken C, Kamen DL, Wagner M, Bals R, Steinmeyer A, Zugel U, Gallo RL, Eisenberg D, Hewison M, Hollis BW, Adams JS, Bloom BR, Modlin $\mathrm{RL}$ : Toll-like receptor triggering of a vitamin D-mediated human antimicrobial response. Science 2006, 311:1770-1773.

14. Shoji T, Shinohara K, Kimoto E, Emoto M, Tahara H, Koyama H, Inaba M, Fukumoto S, Ishimura E, Miki T, Tabata T, Nishizawa Y: Lower risk for cardiovascular mortality in oral 1alpha-hydroxy vitamin D3 users in a haemodialysis population. Nephrol Dial Transplant 2004, 19:179-184.

15. Kong J, Kim GH, Wei M, Sun T, Li G, Liu SQ, Li X, Bhan I, Zhao Q, Thadhani R, Li YC: Therapeutic effects of vitamin D analogs on cardiac hypertrophy in spontaneously hypertensive rats. Am J Pathol 2010, 177:622-631.

16. McGill D, Talaulikar G, Potter JM, Koerbin G, Hickman PE: Over time, highsensitivity TnT replaces NT-proBNP as the most powerful predictor of death in patients with dialysis-dependent chronic renal failure. Clin Chim Acta 2010, 411:936-939.

17. Bucharles S, Barberato SH, Stinghen AE, Gruber B, Piekala L, Dambiski AC, Custodio MR, Pecoits-Filho R: Impact of cholecalciferol treatment on biomarkers of inflammation and myocardial structure in hemodialysis patients without hyperparathyroidism. J Ren Nutr 2012, 22:284-291.

18. Devereux RB, Alonso DR, Lutas EM, Gottlieb GJ, Campo E, Sachs I, Reichek N: Echocardiographic assessment of left ventricular hypertrophy: comparison to necropsy findings. Am J Cardiol 1986, 57:450-458.

19. Matthesen SK, Larsen T, Vase H, Lauridsen TG, Pedersen EB: Effect of potassium supplementation on renal tubular function, ambulatory blood pressure and pulse wave velocity in healthy humans. Scand J Clin Lab Invest 2012, 72:78-86.

20. Pedersen EB, Danielsen $H$, Spencer ES: Effect of indapamide on renal plasma flow, glomerular filtration rate and arginine vasopressin in plasma in essential hypertension. Eur J Clin Pharmacol 1984, 26:543-547.

21. Pedersen EB, Eiskjaer $H$, Madsen B, Danielsen $H$, Egeblad M, Nielsen CB: Effect of captopril on renal extraction of renin, angiotensin II, atrial natriuretic peptide and vasopressin, and renal vein renin ratio in patients with arterial hypertension and unilateral renal artery disease. Nephrol Dial Transplant 1993, 8:1064-1070.

22. Kim HW, Park CW, Shin YS, Kim YS, Shin SJ, Kim YS, Choi EJ, Chang YS, Bang BK: Calcitriol regresses cardiac hypertrophy and QT dispersion in secondary hyperparathyroidism on hemodialysis. Nephron Clin Pract 2006, 102:c21-c29.

23. Park CW, Oh YS, Shin YS, Kim CM, Kim YS, Kim SY, Choi EJ, Chang YS, Bang BK: Intravenous calcitriol regresses myocardial hypertrophy in hemodialysis patients with secondary hyperparathyroidism. Am J Kidney Dis 1999, 33:73-81.

24. Dusso AS, Tokumoto M: Defective renal maintenance of the vitamin D endocrine system impairs vitamin D renoprotection: a downward spiral in kidney disease. Kidney Int 2011, 79:715-729.

25. Jean G, Terrat JC, Vanel T, Hurot JM, Lorriaux C, Mayor B, Chazot C Evidence for persistent vitamin D 1-alpha-hydroxylation in hemodialysis patients: evolution of serum 1,25-dihydroxycholecalciferol after 6 months of 25-hydroxycholecalciferol treatment. Nephron Clin Pract 2008, 110:c58-c65.

26. Dusso A, Lopez-Hilker S, Rapp N, Slatopolsky E: Extra-renal production of calcitriol in chronic renal failure. Kidney Int 1988, 34:368-375.

27. Gonzalez-Parra E, Rojas-Rivera J, Tunon J, Praga M, Ortiz A, Egido J: Vitamin $D$ receptor activation and cardiovascular disease. Nephrol Dial Transplant 2012, 27(4):iv17-iv21.

28. Margolis KL, Ray RM, Van HL, Manson JE, Allison MA, Black HR, Beresford SA, Connelly SA, Curb JD, Grimm RH Jr, Kotchen TA, Kuller LH, WassertheilSmoller S, Thomson CA, Torner JC: Effect of calcium and vitamin D supplementation on blood pressure: the Women's Health Initiative Randomized Trial. Hypertension 2008, 52:847-855. 
29. Sugden JA, Davies Jl, Witham MD, Morris AD, Struthers AD: Vitamin D improves endothelial function in patients with Type 2 diabetes mellitus and low vitamin D levels. Diabet Med 2008, 25:320-325.

30. Scragg R, Khaw KT, Murphy S: Effect of winter oral vitamin D3 supplementation on cardiovascular risk factors in elderly adults. Eur $J$ Clin Nutr 1995, 49:640-646.

31. Larsen T, Mose FH, Bech JN, Hansen AB, Pedersen EB: Effect of cholecalciferol supplementation during winter months in patients with hypertension: a randomized, placebo-controlled trial. Am J Hypertens 2012, 25:1215-1222.

32. Witham MD, Price RJ, Struthers AD, Donnan PT, Messow CM, Ford I, McMurdo ME: Cholecalciferol treatment to reduce blood pressure in older patients with isolated systolic hypertension: the VitDISH randomized controlled trial. JAMA Intern Med 2013.

33. Martin LC, Franco RJ, Gavras I, Matsubara BB, Okoshi K, Zanati SG, Caramori JT, Barretti P, Balbi AL, Gavras H: Is 44-hour better than 24-hour ambulatory blood pressure monitoring in hemodialysis? Kidney Blood Press Res 2006, 29:273-279.

34. Blacher J, Guerin AP, Pannier B, Marchais SJ, Safar ME, London GM: Impact of aortic stiffness on survival in end-stage renal disease. Circulation 1999, 99:2434-2439.

35. Hewitt NA, O'Connor AA, O'Shaughnessy DV, Elder GJ: Effects of cholecalciferol on functional, biochemical, vascular, and quality of life outcomes in hemodialysis patients. Clin J Am Soc Nephrol 2013, 8:1143-1149.

36. Di IB, Nazzaro P, Cucciniello E, Bellizzi V: Influence of haemodialysis on variability of pulse wave velocity in chronic haemodialysis patients. Nephrol Dial Transplant 2010, 25:1579-1583.

37. Bouillon $R$, Carmeliet $G$, van EE Verlinden L, Verstuyf A, Luderer HF, Lieben L, Mathieu C, Demay M: Vitamin D and human health: lessons from vitamin D receptor null mice. Endocr Rev 2008, 29:726-776.

38. Kong J, Qiao G, Zhang Z, Liu SQ, Li YC: Targeted vitamin D receptor expression in juxtaglomerular cells suppresses renin expression independent of parathyroid hormone and calcium. Kidney Int 2008, 74:1577-1581

39. Larsen T, Mose FH, Bech JN, Pedersen EB: Effect of paricalcitol on renin and albuminuria in non-diabetic stage III-IV chronic kidney disease: a randomized placebo-controlled trial. BMC Nephrol 2013, 14:163.

40. de ZD Agarwal R, Amdahl M, Audhya P, Coyne D, Garimella T, Parving HH, Pritchett $Y$, Remuzzi G, Ritz E, Andress D: Selective vitamin D receptor activation with paricalcitol for reduction of albuminuria in patients with type 2 diabetes (VITAL study): a randomised controlled trial. Lancet 2010, 376:1543-1551.

41. Jean G, Terrat JC, Vanel T, Hurot JM, Lorriaux C, Mayor B, Chazot C: Daily oral 25-hydroxycholecalciferol supplementation for vitamin $D$ deficiency in haemodialysis patients: effects on mineral metabolism and bone markers. Nephrol Dial Transplant 2008, 23:3670-3676.

42. Jean G, Souberbielle JC, Chazot C: Monthly cholecalciferol administration in haemodialysis patients: a simple and efficient strategy for vitamin $D$ supplementation. Nephrol Dial Transplant 2009, 24:3799-3805.

43. Tokmak F, Quack I, Schieren G, Sellin L, Rattensperger D, Holland-Letz T, Weiner SM, Rump LC: High-dose cholecalciferol to correct vitamin D deficiency in haemodialysis patients. Nephrol Dial Transplant 2008, 23:4016-4020

44. Stubbs JR, Idiculla A, Slusser J, Menard R, Quarles LD: Cholecalciferol supplementation alters calcitriol-responsive monocyte proteins and decreases inflammatory cytokines in ESRD. J Am Soc Nephrol 2010, 21:353-361.

45. Shah N, Bernardini J, Piraino B: Prevalence and correction of $25(\mathrm{OH})$ vitamin D deficiency in peritoneal dialysis patients. Perit Dial Int 2005, 25:362-366.

doi:10.1186/1471-2369-15-50

Cite this article as: Mose et al:: Cardiovascular effects of cholecalciferol treatment in dialysis patients - a randomized controlled trial. BMC Nephrology 2014 15:50.

\section{Submit your next manuscript to BioMed Central and take full advantage of:}

- Convenient online submission

- Thorough peer review

- No space constraints or color figure charges

- Immediate publication on acceptance

- Inclusion in PubMed, CAS, Scopus and Google Scholar

- Research which is freely available for redistribution

Submit your manuscript at www.biomedcentral.com/submit
Ciomed Central 